\title{
A QUALITATIVE PILOT ASSESSMENT OF ORAL HEALTH INFORMATION DELIVERED IN THE MEDICAL HOME
}

\author{
Melani B. Decker
}

A thesis submitted to the faculty at the University of North Carolina at Chapel Hill in partial fulfillment of the requirements for the degree of Master of Science in Dental Hygiene Education in the Department of Dental Ecology in the School of Dentistry.

Chapel Hill

2015

Approved by:

Rocio B. Quinonez

R. Gary Rozier

Paul G. Mihas

Rebecca S. Wilder

Mike Steiner 
(C) 2015

Melani B. Decker

ALL RIGHTS RESERVED 


\begin{abstract}
Melani B. Decker: A Qualitative Pilot Assessment of Oral Health Information Delivered in the Medical Home

(Under the direction of Rocio B. Quinonez)

This pilot study aimed to describe the inclusion of oral health counseling and communication techniques during medical visits. We evaluated 15 transcripts of caregiver-provider interactions during medical visits for 0-42 month old children.

Preventive messages by five providers participating in a Medicaid preventive oral health initiative in North Carolina were evaluated. The American Academy of Pediatrics (AAP) 2008 oral health guidelines and American Dental Association's communication domains were used as standards to examine oral health information and caregiver-provider communication styles. A total of 9 sick and 6 well-child transcribed interactions were examined. Oral health counseling occurred during all medical visits with topical fluoride most frequently discussed and establishment of a dental home/referral least frequently reviewed. Interpersonal communication domain "present two to three topics at one time" was most commonly used. In this pilot sample, AAP oral health guidelines are being followed, but gaps remain regarding referral to a dental home.
\end{abstract}




\section{ACKNOWLEDGEMENTS}

I would like to express my sincere gratitude to the University of North Carolina School of Dentistry for facilitating my earning of a Master's Degree. The vast knowledge, guidance, and patience of Rocio Quinonez cannot be overstated; my deepest thanks to her for teaching me so much. Thank you to my committee members Dr Gary Rozier, Mr Paul Mihas, Professor Rebecca Wilder and Dr Mike Steiner for their expertise and willingness to provide input. A special thank you to the original investigators, Ashley Kranz, and Bhavna Pahel for their gathering and painstaking transcription of the data. This project would not have been possible without their initial diligent work.

I am grateful to my DHED colleagues, the School of Dentistry faculty and staff, as well as students, who all contributed to my growth as a professional during my time at UNC. Finally, I would like to acknowledge the constant love and support of my husband, Adam and the encouragement that we both received from our families. 


\section{TABLE OF CONTENTS}

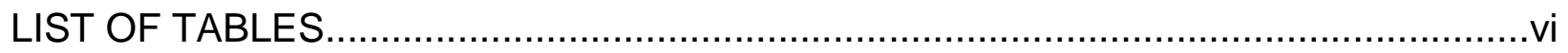

LIST OF ABBREVIATIONS......................................................................................

\section{CHAPTER}

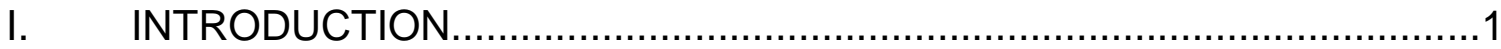

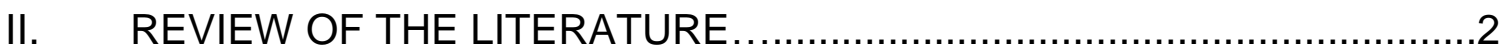

III. INTRODUCTION AND REVIEW OF THE LITERATURE.........................6

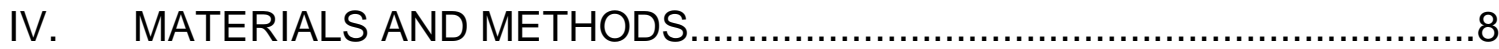

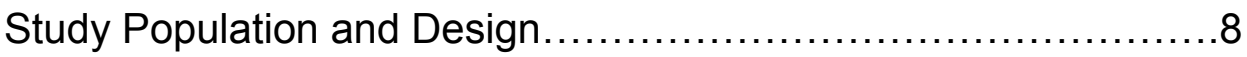

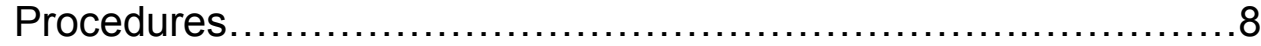

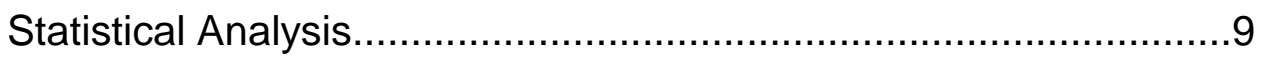

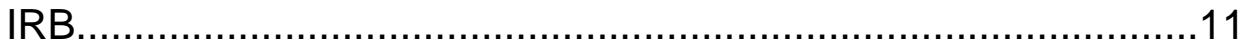

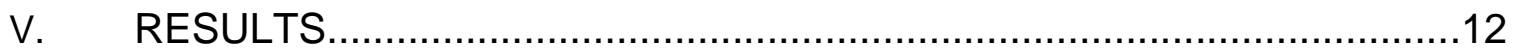

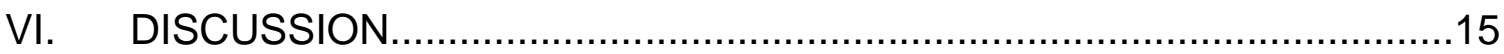

Strengths and Limitations....................................................19

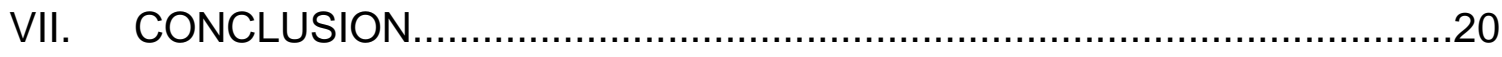

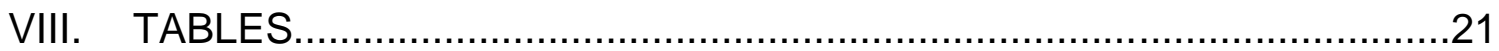

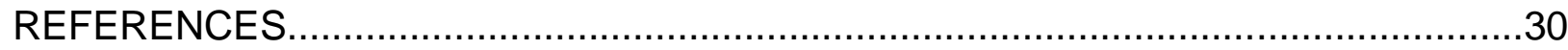




\section{LIST OF TABLES}

Table 1a. Study Domains Using the American Academy of Pediatrics Oral Health

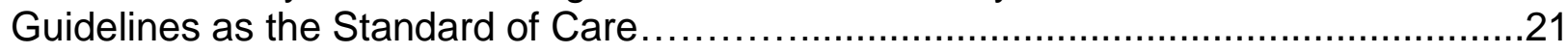

Table 1b. Communication Techniques using the American Dental Association

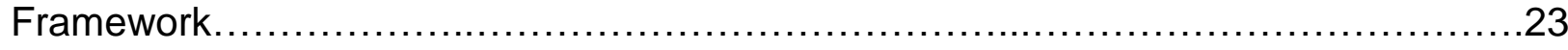

Table 2 Frequency of AAP Oral Health Guidelines per Non-well and Well Visits in

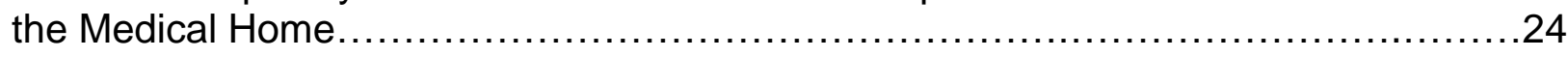

Table 3. Frequency of ADA Communication Domains per Sick and Well Visits in the

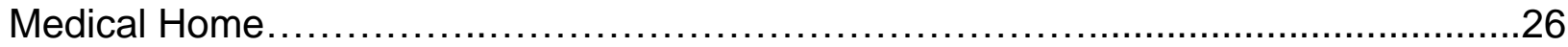

Table 4: Sequential Analysis of Fifteen Transcripts (Abridged Version/Selected Interactions) 


\section{LIST OF ABBREVIATIONS}

AAP American Academy of Pediatrics

ADA American Dental Association

AMA American Medical Association

ECC Early Childhood Caries

IMB Into the Mouths of Babes

QAE Question, Answer/Advise, Explanation 


\section{INTRODUCTION}

Delivery of preventive oral health services in the medical home can increase access to care and decrease caries related treatment for children with frequent visits in the first three years of life. ${ }^{1}$ North Carolina's adoption of the Into the Mouths of Babes (IMB) program was effective in reducing caries-related treatments in early childhood. Children with more than four IMB visits benefited from bundled oral health preventive services, including risk assessment, counseling, oral health screening and referral to a dental home. ${ }^{2}$ Peirce et al. concluded in 2002 that primary care providers in North Carolina accurately identify carious lesions with proper training. and preliminary studies in the state of North Carolina show physician and auxiliary interest and competency in providing preventive oral health services to Medicaid eligible children. ${ }^{3}$ 


\section{REVIEW OF THE LITERATURE}

In Pahel's study, researchers used enrollment data and longitudinal claims (0-72 months) in Medicaid enrolled children to assess the influence of frequent oral health preventive services in the medical home. To combat oral health disparities in access to care, the North Carolina Medicaid program compensates pediatric primary care providers for preventive services they deliver to low-income children younger than $3^{1 / 1} 2$ years old. The IMB program, trains physicians and auxiliary to provide parent counseling, screenings and referrals and topical fluoride varnish to eligible patients. It has previously been established that this program successfully trains providers, increases access to care and reduces need for treatment. ${ }^{2}$

Good clinical practice revolves around communication; therefore communication training and assessment are key components in medical curriculum. ${ }^{4}$ Research has established that communication during physical exams is understudied. - $^{4-6}$ One study by Slade et. al. evaluated the effects of continuing medical education on the delivery of preventive dental services by medical personnel in primary care offices. Results showed a high proportion of medical practices capable of adopting preventive services. ${ }^{7}$

Part of the preventive dental visit at a medical office includes patient education. Both the provider (student or graduate) and patient or caregiver utilizes communication techniques during education portions of medical visits. Clinical-practice texts refer to provider-patient communication during exams, but lack development in effectiveness. 
In medicine, lessons on communication skills do not provide specific guidance concerning effectiveness or process. ${ }^{4}$

Complicating the process further, a well-child visit naturally involves a third party: the parent or guardian. Triadic communication can be challenging, particularly when involving healthcare. A 2013 study by Laidsaar-Powell et al. considered 52 encounters of adult triadic communication (spouse/partner/adult child-patient-provider). In this research they identified three strategies for providers to implement in communication involving more than one subject, the patient. Encouraging and involving the companions was determined to be useful. Identifying helpful spousal activities and clarifying and agreeing on roles were two other strategies recognized for optimizing triadic consultations. ${ }^{6}$

Opel et. al. determined the achievability of using direct observation of providerparent immunization discussions to characterize providers' communication practices. Minimal data regarding how pediatricians communicate is available and can be credited for the absence of a communication standard for vaccine-hesitant parents and providers. ${ }^{5}$ Further research is necessary to identify the best approach to explore communication during physical examination, and how this is taught and learned.

Effectiveness of training for pediatric health care providers on oral health has been studied. North Carolina has implemented the use of the training program "Connecting the Docs" to achieve such preparation. A pilot study of one training program done in 2007 concluded that a large percentage of medical practices are 
capable of adopting preventive dental services. ${ }^{7}$ The delivery of trainings were tested in three groups: didactic training, didactic training plus weekly conference calls and didactic, weekly conference calls and in-office hands-on training. The results showed no difference in adoption and compliance between the three groups. ${ }^{7}$ An increase in referrals to dental offices, therefore earlier detection, was reported in the "Into the Mouths of Babes" program. ${ }^{2}$ Inter-professional cooperation and program adoption are key elements in training programs' success.

The incorporation of these services is echoed by the American Academy of Pediatrics' (AAP) most recent oral health policy statement and the forty-five states that reimburse Medicaid eligible children to receive these services in the medical home..$^{8-9}$ In North Carolina, the physician based program, called Into the Mouths of Babes (IMB), trains providers to deliver caregiver oral health counseling, screenings, referral to a dental home, and topical fluoride varnish to eligible patients.

While providers are required to discuss oral health related anticipatory guidance, including oral homecare, diet, use of topical and systemic fluoride as part of IMB, little is known about the level of discussion in which these topics emerge during well and sick child visits.

Communication between providers and patients in the medical home has been under investigated. ${ }^{4-6}$ Clinical-practice texts refer to provider-patient communication during exams, but lack assessment of its effectiveness and process. ${ }^{4}$ Cleland et al call for further research to help enlighten how best to explore communication in clinical practice, how it is taught and learned. Specific to oral health, provider recommendations have been documented to influence oral health related behaviors. 
For example, a study performed in 69 pediatric practices and 49 family medicine practices demonstrated that caregivers referred to a dental home by their provider during their well-child visit in the presence of early childhood caries were more likely to follow up than those who had disease but no documentation of a referral was made. ${ }^{1}$ Similarly, Beil et al reported children ages 2 to 5 year being nearly 3 times more likely to visit the dentist when a recommendation was made by a physician or another health care provider. ${ }^{10}$ Understanding how health care providers' communicate and the content of the information delivered can have help influence health promotion, disease prevention and training. 


\section{INTRODUCTION AND REVIEW OF THE LITERATURE}

Delivery of preventive oral health services in the medical home can increase access to care and decrease caries related treatment for children with frequent visits in the first three years of life. ${ }^{2}$ The incorporation of these services is echoed by the American Academy of Pediatrics' most recent oral health policy statement (AAP, 2014) and the forty-five states that reimburse Medicaid eligible children to receive these services in the medical home. ${ }^{8-9}$ In North Carolina, the physician based program, called Into the Mouths of Babes (IMB), trains providers to deliver caregiver oral health counseling, screenings, referral to a dental home, and topical fluoride varnish to eligible patients. While providers are required to discuss oral health related anticipatory guidance, including oral homecare, diet, use of topical and systemic fluoride as part of IMB, little is known about the level of discussion in which these topics emerge during well and sick child visits.

Communication between providers and patients in the medical home has been under investigated. ${ }^{4-6}$ Clinical-practice texts refer to provider-patient communication during exams, but lack assessment of its effectiveness and process. ${ }^{4}$ Cleland et al call for further research to help enlighten how best to explore communication in clinical practice, how it is taught and learned. Specific to oral health, provider recommendations have been documented to influence oral health related behaviors. 
For example, a study performed in 69 pediatric practices and 49 family medicine practices demonstrated that caregivers referred to a dental home by their provider during their well-child visit in the presence of early childhood caries were more likely to follow up than those who had disease but no documentation of a referral was made. ${ }^{1}$ Similarly, Beil et al reported children ages 2 to 5 year being nearly 3 times more likely to visit the dentist when a recommendation was made by a physician or another health care provider. ${ }^{10}$ Understanding how health care providers' communicate and the content of the information delivered can have help influence health promotion, disease prevention and training.

Thus, the purpose of this pilot study is to describe caregivers-providers oral health related interactions during medical visits and among a group of 15 primary care providers who had undergone training in NC's IMB physician oral health program. It was our goal to compare oral health communication during these visits using the AAP's oral health guidelines for messages referring to counseling and referral to a dental home, and the American Dental Association's (ADA) communication style framework for the caregiver-provider interaction. This pilot study can assist in future research to help maximize integration of oral health preventive messaging in the medical home. 


\section{MATERIALS AND METHODS}

\section{Study population and design}

Participants resided in central North Carolina and were all English speaking, Medicaid-enrolled, and caregivers of 6-42 month old children. Using a cross-sectional study design and secondary data, we reviewed 15 medical transcripts of caregiverprovider interactions.

\section{Procedures}

Following the University of North Carolina's Institutional Review Board's approval, transcripts from a previous study capturing caregiver-provider interaction through audio-recording of medical visits were obtained. ${ }^{9}$ Informed consent had been achieved from 4 pediatricians and 1 physician's assistant at a pediatric office in North Carolina that had been trained in delivering preventive oral health services through the IMB program. Prior to the original data collection, study participants were explained the three-phase process, namely: baseline questionnaire, audiotaping of the child's medical visit, and a post-visit questionnaire. Upon completion of the first questionnaire, caregivers and patients continued their visit in the examination room where a tape recorder was turned on before the provider entered. Caregivers were aware that they could request the recorder be turned off at any point during the visit. The study representatives were not present in the exam room during the recording, and returned to turn the recorder off after the provider exited the room. 
When all encounters were completed, recordings of all medical visits were transcribed and reviewed for completeness. The fifteen de-identified provider-caregiver medical visit transcripts were obtained and were the only component used for the current study.

\section{Statistical Analysis}

All transcripts were uploaded into the qualitative data analysis software MaxQDA. Using standards established by the AAP and the ADA, data was coded for content (oral health messages) and delivery (communication style) (Table 1a and 1b). The AAP standards were used to examine broad oral health related domains content, including screening, counseling (solid and liquid diet, oral hygiene practices, fluoride) and referral to a dental home. To assess provider communication styles during oral health messaging, we used the ADA's communication technique framework focused on the presence of the five interpersonal communication techniques and two teach-back techniques used commonly in health communications.

Table $1 \mathrm{~b}$ describes how communication techniques were coded using the seven ADA recognized domains; five "interpersonal communication" and two "teach-back". The seven domains were originally adopted from the American Medical Association's recommended communication techniques. For example, the technique of "presenting two-to-three concepts at one time" was recorded when the provider addressed only two or three ideas before moving onto a different subject. This code was used when the provider spoke about a topic, such as fluoride-use, without any further questions from the caregiver or patient and the provider presented no new information before moving onto another topic. If the provider used laymen's terms when discussing oral health 
topics, the text was coded as "simple language"; for example, when a medical provider made reference to dental caries using "decay" or "cavity".

The interpersonal communication technique "teach-back" was coded when a provider, medical or otherwise, asked their patient (or caregiver in some instances) to repeat or show the provider their interpretation of the message they just received. An example of this was after a provider discusses tooth brushing with a caregiver and patient, he or she asks the caregiver and patient to show him or her how they will implement the instructions given at home. "Teach-back" can also be done verbally; whereby the caregiver/patient explains what they will do at home to adhere to the provider's advice.

In addition to the deductive codes that were used from the ADA communication framework, the researchers also identified several emerging codes related to communication techniques. Identifying inductive codes is a strength of qualitative analysis and provides a richer codebook for follow-up studies.

Because particular codes followed each other in interactions between providers and caregivers, qualitative proximity coding was used to consistently identify communication patterns comprised of specific interpersonal communication approaches. That is, in analyzing codes that occurred sequentially, a type of proximity coding, we were able to identify patterns of codes adjacent to or overlapping other codes. The Sage Handbook of Qualitative Data Analysis discusses proximity coding as a speculative approach to explore data. ${ }^{11}$ The rationale for analyzing codes sequentially related to other codes is that this close review provides a more nuanced understanding of the provider-caregiver interaction and how the communication techniques play out 
across interactions. This attention to sequential patterns is common in conversation analysis but can also benefit more pragmatic qualitative studies. ${ }^{12}$

One primary researcher coded the data but a second coder reviewed over $40 \%$ of the coded text. Coding consensus meetings with the second coder also provided ongoing opportunities to discuss emerging codes, specific application of codes, and directions for analysis.

IRB

This study was considered exempt by the Biomedical Institutional Review Board of the University of North Carolina at Chapel Hill (UNC). 


\section{RESULTS}

The transcripts revealed that when providers are trained on the inclusion of oral health information during the medical visit (IMB), they discussed oral health with their patients in both well and sick child visits (Table 2). In addition to performing oral screenings, anticipatory guidance messages included solid and liquid diet, homecare (ie toothbrushing), topical and systemic fluorides, and establishing a dental home for their child. Many of the oral health topics identified in the transcripts were consistent with those delineated in the AAP guidelines. Results indicated two major themes emerging.

\section{Theme 1: Oral health messaging/information}

The most significantly overlooked topic identified was a referral to a dental home. Even under the most optimal circumstances among providers that received IMB training, establishing a dental home occurred in one-third of the visits ( 3 well visits and 2 sick visits), with interactions being brief. An example of a brief dental home discussion

was seen in ID 2, "If we notice that he has a problem with his teeth at a young age, we'll send him to a dentist." Conversely, topical fluoride was the most commonly discussed topic, with interactions about fluoride being more involved and longer in the text.

\section{Theme 2: Communication techniques}

A second emerging theme was interpersonal communication as the most commonly used method of delivering oral health information in the recorded interactions (Table 3). It was commonly utilized in "presenting two-three concepts at one time", with "teachback" domain as nominal. When presenting multiple oral health concepts at a time, 
providers frequently used a sequence of questioning, answering/advising, and explaining. (We abbreviate this pattern as QAE.) The interaction in ID 2 illustrates communication techniques utilizing numerous QAE sequences and simple language (Table 4). When this sequence occurred, it was recurrently accompanied by use of simple language, presenting two to three concepts at one time, or both. Providers asked questions about how tooth brushing was done at home, but never asked caregivers or patients to repeat or show them how they perform these behaviors ("teach-back").

Qualitative proximity coding used to identify sequential communication patterns within the data provided more in-depth information on how each individual interaction transpired. The sequential analysis provided insight into communication in analyzing caregiver-provider/patient interactions. The sequence of questioning, answering/advising and explaining (QAE) occurred in over half of the 15 interactions. Other combinations of these codes (and corresponding acronyms) were used when fewer than three of these codes were evident or if they occurred in a different order. In $27 \%$ of the interactions, the pattern QA emerged; $13 \%$ of interactions had an $\mathrm{AE}$ sequence, and one interaction had no notable pattern of any QAE variation.

As displayed in Table 4, ID 12 is an example of a QA interaction; the questioning and answering/advising sequence occurred without the explanation piece. In contrast, ID 2 includes all three pieces of the coded QAE sequence. The pilot nature of this study cannot claim the use of a QAE as the ideal arrangement for caregiver-provider-patient interactions, but an example of a QAE sequence, compared to a $\mathrm{QA}$ or $\mathrm{AE}$, indicates a richer exchange of information between the provider and caregiver. 
The coders assessed the question of data saturation by analyzing frequency tables of deductive and emerging codes to assess how codes had been applied across transcripts. Sandelowski describes data saturation, or informational redundancy, as the point when a researcher has seen and heard the same thing over and over again. ${ }^{13}$ After coding for the inductive codes, reviewing frequency tables (and application of codes) allowed us to determine that no new relevant codes were evident during the iterative coding process and that all deductive codes from the codebook had been applied to the appropriate text. However, because this study was based on a predetermined number of transcripts, we are cautious of the claim of data saturation. Nevertheless, we should note that Guest et al, in an experiment with data saturation and variability, found that $92 \%$ of the codes in a study emerged after coding the first 12 documents. ${ }^{14}$ 


\section{DISCUSSION}

While studies have shown success in the inclusion of oral health information in the medical home, limited research exists on the quality of its delivery. ${ }^{2,7,15}$ This study used qualitative methodology to provide a deeper, more descriptive understanding of 15 caregiver-provider interactions. The transcripts revealed that providers incorporate preventive oral health messages and referral as part of the medical visit, albeit in a variable manner and using few communication styles.

Specific to the content of oral health messages, providers incorporated the majority of the AAP oral health guidelines, including oral screening, dietary counseling, oral hygiene, fluoride recommendations, and referral. Dietary practices, including juice and sippy-cup were prominently discussed in the transcripts. The overlap of oral and systemic health could explain the frequent occurrence in discussing liquid diet related topics, including juice intake and how it relates to obesity and early childhood caries (ECC). Nelson et al. reported beverage intake as the most common diet-related topic asked to caregivers by pediatricians; occurring in $95.9 \%$ of the medical interactions. ${ }^{16}$ This was similar to our findings, whereby providers specifically highlighted the effects of the sugar content of juices on the oral cavity, particularly with frequent daytime exposure from a sippy-cup.

Of all the oral health related messages discussed during the medical visits, referral to a dental home occurred less frequently than other standards. While our data does not 
provide sufficient evidence to the cause of this, it is a notable topic to prioritize for future oral health trainings of medical providers. To truly promote collaborative care and the link between the medical and dental home, having medical providers emphasize referrals is key as it can influence caregiver's behaviors on following up with a visit to the dentist. ${ }^{1,10}$ Equally important, however, is having dentists able and willing to accept these referrals. Efforts to promote this link are necessary as few dentists accepting publically insured children under age three years has been reported in a national survey of AAP fellows as an important barrier to referral. ${ }^{17}$

It is noteworthy that this pilot study was performed under optimal circumstances, as providers were trained in the North Carolina IMB program and were aware that they were being audio recorded. The transcripts also included both well and sick visits, making the discussion of oral health during sick visits less likely given its more problem based focus. Nevertheless, we believe that the incorporation of fluoride varnish application as part of IMB during sick visits helped emphasize broader oral health conversation that would otherwise be less likely to occur. For example, the topic of fluoride was not limited to fluoride varnish in all cases, but was expanded to the importance of fluoridated toothpaste home use as well as systemic fluoride, such as water fluoridation. These findings are consistent with pediatricians' belief in their significant role in oral health, including $74 \%$ affirming their willingness to apply fluoride varnish. ${ }^{17-18}$ In our study sample, fluoride use was discussed in $80 \%$ of the interactions; with $73 \%$ specifically referencing fluoride varnish.

Interpersonal communication technique, "presenting only two to three concepts at one time", was most frequently used during the caregiver-provider interactions. The 
ADA reports seven common communication domains occurring in dentist-patient messaging in the dental practice. ${ }^{19}$ Horowitz et al. (2013) noted that over $90 \%$ of surveyed dental hygienists self-reported routinely using simple language as a communication technique with their patients. Additionally, responding providers who had received additional instruction in communication beyond dental hygiene school used recommended communication techniques more often than their counterparts without further training did. ${ }^{20}$ Another self-reported survey found that when asked, $75 \%$ of orthopedic surgeons surveyed believed that they communicated satisfactorily, but only $21 \%$ of the patients recounted satisfactory communication with their doctors. ${ }^{21}$ Specific to pediatric care, Isong et al reported that caregivers valued pediatrician's advice on oral healthcare, but did not feel that they receive adequate information, with most of the parents of children with a history of ECC claiming to receive erroneous or no oral health information at their medical visits..$^{22}$ It is imperative to provide training in communication techniques and proper oral health content to maximize providers' influence on caregiver's oral health behaviors and health outcomes.

Our findings highlighted that "teach-back" was underutilized, appearing in none of the 15 interactions. Experts in health quality improvement support teach-back methodology as it allows for confirmation of presented information to the patient, caregiver, or both. ${ }^{23}$ Peter et al., studied the impact of utilizing teach-back when communicating with patients with heart failure. Their study noted $12 \%$ lower readmission after initial hospitalization in patients that were counseled using the "teachback" technique when compared to a control group who did not utilize this communication practice. ${ }^{24}$ The limited use of "teach-back" in our study could be a 
missed opportunity to confirm oral health messages are being received as their intended delivery. This is an important consideration to future provider training, particularly given that communication skills training can improve doctor-patient communication by positively influencing patients' emotions and expedite understanding of potentially confusing medical information. ${ }^{25-29}$

A sequential communication pattern of questions, answers/advice, explanation (QAE) was identified using proximity coding. Examining how each individual interaction transpired allowed us to assess communication patterns and identify differences between information exchanges in a QAE versus a QA sequence. The use of an explanation following a dictum or advice allowed providers to elaborate with a "why" and not just a "what" when delivering oral healthcare information in the medical home. Even in this small sample, we note that QAE provided more opportunities for using simple language and 2-3 concepts at a time because the explanations allowed for further elaboration on a topic prior to moving onto the next subject. This study cannot address whether an interaction providing explanation as well as advice will impact behavior change more than an interaction using another approach, but identifying the presence of QAE in some encounters and its absence in others raises the question of preferable communication techniques beyond what the literature has established. Future studies should examine how caregivers experience QAE (and other combinations of questions, answers/advice, and explanations) in the context of disseminating relevant oral health information. This may help address caregiver's perception of adequate oral health care information received in the medical or dental home. ${ }^{22}$ 


\section{Strengths and Limitations}

This study should be assessed in the context of its limitations. First, the small sample size and single medical practice examined provides limited generalizability, although there are many clinical practices similar to the one reported. A larger sample size may depict more variety in content and communication styles. Second, the providers in this study were previously trained in the delivery of oral health information and its implementation into clinical practice. The IMB training created an optimal scenario to deliver oral health messages, but cannot account for providers that have not had any preceding, explicit training. 


\section{CONCLUSIONS}

This pilot study provides insight into the depth of oral health information delivered in the medical home by five providers trained in pediatric preventive oral health services. As we continue to work towards training a primary healthcare workforce to become a partner in addressing pediatric oral health issues, exploring ways to effectively integrate and communicate relevant messages is paramount to maximizing children's oral health. Future qualitative research with larger samples is necessary to further examine provider's communication styles, techniques and their influence on oral health outcomes in the medical home. 


\section{TABLES}

Table 1a: Study Domains Using the American Academy of Pediatrics Oral Health Guidelines as the Standard of Care

\begin{tabular}{|c|c|}
\hline PILOT STUDY DOMAINS & American Academy of Pediatrics (AAP) Guidelines \\
\hline Screening & $\begin{array}{l}\text { Oral Health Screening } \\
\text { - } \text { Determine whether tooth eruption and loss are proceeding according to schedule } \\
\text { - Assess tooth irregularities and alignment of teeth } \\
\text { - Demonstrate to the parent how to remove plaque and debris using the appropriate size toothbrush } \\
\text { - } \text { Asrectly. } \\
\circ \quad \text { Tooth decay } \\
\circ \text { Malocclusions (improper alignment of the jaws and teeth) } \\
\circ \text { Oral injuries } \\
\circ \text { Other risk factors }\end{array}$ \\
\hline $\begin{array}{l}\text { Diet: Liquid (bottle/milk) } \\
\text { Diet: Liquid (juice/sippy cup) }\end{array}$ & $\begin{array}{l}\text { Dietary Counseling } \\
\text { - Parents and caregivers should be counseled on the importance of reducing exposure to sugars in foods } \\
\text { and drinks }\end{array}$ \\
\hline $\begin{array}{l}\text { Fluoride: systemic } \\
\text { Fluoride: topical }\end{array}$ & $\begin{array}{l}\text { Optimal Use of Fluorides } \\
\text { - Community-based fluorides } \\
\text { - Professionally applied fluorides } \\
\text { - Self-administered fluorides }\end{array}$ \\
\hline $\begin{array}{l}\text { Oral Hygiene: Parent } \\
\text { Brushing } \\
\text { Oral Hygiene: No brushing } \\
\text { Oral Hygiene: Child } \\
\text { brushing }\end{array}$ & $\begin{array}{l}\text { Anticipatory Guidance } \\
\text { - Oral Hygiene Instruction } \\
\text { - } \quad \text { Agunseling regarding nonnutritive oral habits } \\
\text { - Age appropriate information regarding dental injury prevention }\end{array}$ \\
\hline Dental Home & $\begin{array}{l}\text { Interprofessional Collaboration and Establishment of a Dental Home } \\
\text { - Dental home established within } 6 \text { months of eruption of first tooth but no later than } 12 \text { months of age }\end{array}$ \\
\hline
\end{tabular}


Table 1b: Communication Techniques using the American Dental Association Framework

\begin{tabular}{|c|c|}
\hline $\begin{array}{l}\text { Domains: Communication } \\
\text { Techniques }\end{array}$ & Criteria for coding \\
\hline \multicolumn{2}{|l|}{ Interpersonal Communication } \\
\hline $\begin{array}{l}\text { - Present two to three concepts at a } \\
\text { time }\end{array}$ & $\begin{array}{l}\text { The provider presented two to three } \\
\text { concepts at one time. For example } \\
\text { - when discussing oral hygiene, the } \\
\text { provider did not bring in other } \\
\text { topics such as diet. }\end{array}$ \\
\hline $\begin{array}{l}\text { - Ask patients whether they would like } \\
\text { a family member or friend involved in } \\
\text { the discussion }\end{array}$ & $\begin{array}{l}\text { The provider asks the caregiver if } \\
\text { they would like a family member or } \\
\text { friend involved in the discussion. }\end{array}$ \\
\hline $\begin{array}{l}\text { Draw pictures or use printed } \\
\text { illustrations }\end{array}$ & $\begin{array}{l}\text { Looked for vocabulary consistent } \\
\text { with use of pictures/illustrations. } \\
\text { For example - "Let me draw this for } \\
\text { you" or "Do you see in this } \\
\text { picture..." }\end{array}$ \\
\hline - Speak Slowly & $\begin{array}{l}\text { This was not coded as it is } \\
\text { undetectable on paper transcripts. }\end{array}$ \\
\hline - Use Simple Language & $\begin{array}{l}\text { The provider used lay oral health } \\
\text { terms rather than medical and } \\
\text { dental jargon }\end{array}$ \\
\hline \multicolumn{2}{|l|}{ Teach-Back Method } \\
\hline $\begin{array}{l}\text { - Ask patients to repeat information or } \\
\text { instructions back to you }\end{array}$ & $\begin{array}{l}\text { The provider asked the caregivers } \\
\text { to repeat instructions they were } \\
\text { given. }\end{array}$ \\
\hline $\begin{array}{l}\text { - Ask patients to tell you what they will } \\
\text { do at home to follow instructions }\end{array}$ & $\begin{array}{l}\text { The provider asked the caregivers } \\
\text { what they would do at home from } \\
\text { here forward to follow the } \\
\text { instructions given. }\end{array}$ \\
\hline
\end{tabular}


Table 2: Frequency of AAP Oral Health Guidelines per Non-well and Well Visits in the Medical Home

\begin{tabular}{|c|c|c|c|c|}
\hline & $\begin{array}{l}\text { Non-well } \\
\text { Visits } \\
(\mathrm{N}=10)\end{array}$ & $\begin{array}{l}\text { Well } \\
\text { Visits } \\
(\mathrm{N}=5)\end{array}$ & $\begin{array}{l}\text { Total } \\
\text { Visits } \\
(\mathrm{N}=15)\end{array}$ & Quote from Transcripts \\
\hline \multicolumn{5}{|l|}{ Guidelines } \\
\hline Screening & 9 & 4 & 13 & $\begin{array}{l}\text { P: let's take a look at your throat. A little ulcers right there... } \\
\text { C: I didn't notice it til now, but she's got these little bumps on her thumb and on her tongue. } \\
\text { P: Yes, there are little ulcers. The ulcers are usually caused by viruses. Just lean back girl...Okay, I took a look at her } \\
\text { mouth and I don't see any plaque in her teeth. }\end{array}$ \\
\hline Diet: Solid & 2 & 5 & 7 & P: So not doing the fruit snacks and fruit juice in between. \\
\hline $\begin{array}{l}\text { Diet: Liquid } \\
\text { (milk/bottle) }\end{array}$ & 0 & 2 & 2 & $\begin{array}{l}\text { P....Just remember to get rid of the intermittent stuff in the day. I'm really glad you don't go to bed with a bottle because } \\
\text { that's the most important thing. } \\
\text { C: Oh no, say no sir. She never had a bottle. }\end{array}$ \\
\hline $\begin{array}{l}\text { Diet: Liquid } \\
\text { (juice/sippy cup) }\end{array}$ & 7 & 6 & 13 & $\begin{array}{l}\text { P: What does she get to drink? } \\
\text { C: She gets juice, all kinds juice, she gets whole milk, and water. } \\
\text { P: Is she off the bottle? } \\
\text { C: Umm hmm. } \\
\text { P: So the bottle is long and gone? } \\
\text { C: Yes } \\
\text { P: My biggest suggestion on that part is to really watch the juices, okay? There's not a whole of juice that they need. It's } \\
\text { one of the worst things they can do for the weight and teeth. The worst way to do a juice is the give them a sippy cup and } \\
\text { let them walk around with it all day. That's constantly exposing her teeth to sugar and that's going to cause a problem. If } \\
\text { you're going to do juice, I would do maybe an once or two at a specific time, but not at all day. The big day thing I like to } \\
\text { tell people to drink is milk or water. }\end{array}$ \\
\hline $\begin{array}{l}\text { Oral Hygiene: } \\
\text { Parent Brushing }\end{array}$ & 6 & 5 & 11 & $\begin{array}{l}\text { P:...So what about those teeth? Are you cleaning the teeth? } \\
\text { C: Umm hmm. } \\
\text { P: And how do you do it? } \\
\text { C: Umm, I do it } 2 \text { different ways. I have the little finger brush and sometimes when I'm washing his face he likes to grab } \\
\text { the wash cloth and I just stick my finger in there. } \\
\text { P: Perfect. }\end{array}$ \\
\hline $\begin{array}{l}\text { Oral Hygiene: } \\
\text { Child Brushing }\end{array}$ & 2 & 1 & 3 & $\begin{array}{l}\text { P:... He loves to brush his teeth? } \\
\text { C: Oh yea, he loves to do it. But he won't let us do it. He'll sit there and try to do it himself. } \\
\text { P: How often does he do it? } \\
\text { C: Every day. } \\
\text { P: At least once? } \\
\text { C: Yes, sometimes he'll do it more. He sneaks into the bathroom and he'll steal a toothbrush. }\end{array}$ \\
\hline $\begin{array}{l}\text { Oral Hygiene: No } \\
\text { Brushing }\end{array}$ & 1 & 1 & 2 & $\begin{array}{l}\text { P:...Now with her teeth, is she brushing or are you, or a little bit a both? } \\
\text { C: Yea, well I stopped brushing her teeth because I though the dentist said she was too young. } \\
\text { P: And I think we did talk about that... It is okay to brush her teeth, at her age... }\end{array}$ \\
\hline
\end{tabular}




\begin{tabular}{|c|c|c|c|c|}
\hline Systemic FI2 & 5 & 1 & 6 & $\begin{array}{l}\text { P: Beginning at } 6 \text { months old, any baby who's exclusively breast fed should also be getting fluoride. He's probably on tri- } \\
\text { be-sal, but this is called tri-bi-fluoro. It's the same dose and everything, but its gives him fluoride, which doesn't go } \\
\text { through breast milk very well. Umm, once he's getting water, fluorinated water in juice, or just drinking water, than you } \\
\text { can stop the fluorine water. } \\
\text { C: I think the nursery water has fluoride in it. } \\
\text { P: Oh, well he may not need it then, but l'll write the prescription any way. How much does he get a day at the nursery? } \\
\text { C: Umm, he drinks about half a sippy cup. } \\
\text { P: So maybe about } 2 \text { ounces a day? Okay, well, in general we say that once they get } 4-6 \text { ounces of fluorinated water, } \\
\text { then we don't need to give him it. Let me write the prescription, but double check if the nursery is fluorinated, which it } \\
\text { probably it is. If it is, then you want to measure how much water can fit in his sippy cup and if it's more than } 4 \text { ounces, } \\
\text { then you don't need to give him the fluoride drop. }\end{array}$ \\
\hline Topical FI2 & 20 & 8 & 28 & $\begin{array}{l}\text { P: You'll get stickers when you'll all done. So the nurse is going to come in and do the dental varnish, where typically } \\
\text { what we'll do is dry the teeth off with gauze, and then she's going to paint them with the varnish. It looks likes caramel-it } \\
\text { doesn't taste like caramel-and they're going to paint that on. Her teeth will look brown for about a day, but don't worry } \\
\text { about that, it will wear off. }\end{array}$ \\
\hline Dental Home & 2 & 3 & 5 & $\begin{array}{l}\text { C:...he was having dental problems last year. } \\
\text { P: What kind of problems? } \\
\text { C: He had to have some caps- } \\
\text { P: Who did that? } \\
\text { C: The people in Greenville... } \\
\text { P: It's [dentist name deleted]? } \\
\text { C: Yes. } \\
\text { P: They are very good dentists. Do you still go to them? } \\
\text { C: Well for his regular visits, we go to Maysville Family Dentistry } \\
\text { P: Oh she's good, that's where I go! } \\
\text { C: Me too. But he just had a check-up and she said everything looked pretty good. } \\
\text { D: So he's getting regular dental check ups? } \\
\text { P: Yes. }\end{array}$ \\
\hline
\end{tabular}


Table 3: Frequency of ADA Communication Domains per Sick and Well Visits in the Medical Home

\begin{tabular}{|l|r|r|r|}
\hline & $\begin{array}{r}\text { Sick- } \\
\text { Visits }\end{array}$ & $\begin{array}{c}\text { Well- } \\
\text { Visits }\end{array}$ & Total \\
\hline Provider Communication Behaviors & 0 & 0 & 0 \\
\hline $\begin{array}{l}\text { Interpersonal Communication: } \\
\text { Present two to three concepts at a time }\end{array}$ & 8 & 4 & 12 \\
\hline $\begin{array}{l}\text { Interpersonal Communication: } \\
\text { Involve fam member/friend in discussion }\end{array}$ & 0 & 0 & 0 \\
\hline $\begin{array}{l}\text { Interpersonal Communication: } \\
\text { Illustrations }\end{array}$ & 0 & 0 & 0 \\
\hline $\begin{array}{l}\text { Interpersonal Communication: } \\
\text { Speak Slowly }\end{array}$ & 0 & 0 & 0 \\
\hline $\begin{array}{l}\text { Interpersonal Communication: } \\
\text { Simple Language }\end{array}$ & 9 & 5 & 14 \\
\hline $\begin{array}{l}\text { Teach Back: } \\
\text { Follow Instructions at home }\end{array}$ & 0 & 0 & 0 \\
\hline $\begin{array}{l}\text { Teach Back: } \\
\text { Repeat }\end{array}$ & 0 & 0 & 0 \\
\hline
\end{tabular}


Table 4: Sequential Analysis of Fifteen Transcripts (Abridged Version/Selected Interactions)

\begin{tabular}{|c|c|c|c|c|}
\hline ID & $\begin{array}{c}\text { Type of } \\
\text { Visit }\end{array}$ & Who & Interaction & Style/Pattern \\
\hline ID 2 & Well & $\begin{array}{l}2 \\
\text { adults } \\
\text { present }\end{array}$ & $\begin{array}{l}\text { The provider addresses the (male) child as he/she enters the room. This child was } \\
\text { previously seen for illness, but presents for a well visit at this appointment. The provider } \\
\text { thanks the caregivers for participating in the study and begins discussing the child's } \\
\text { growth, developments, and habits. } \\
\text { The provider uses the questioning, answering/advising, explanation (QAE) structure } \\
\text { when the conversation moves into discussion of diet. The answering/advising and } \\
\text { explaining while using simple language continues with recommendation of fluoride use, } \\
\text { "Beginning at } 6 \text { months old, any baby who's exclusively breast fed should also be getting } \\
\text { fluoride. He's probably on tri-be-sal, but this is called tri-bi-fluoro. It is the same dose } \\
\text { and everything, but its gives him fluoride, which doesn't go through breast milk very well. } \\
\text { Umm, once he's getting water, fluoridated water in juice, or just drinking water, than you } \\
\text { can stop the fluoride water." } \\
\text { Another QAE sequence concerning tooth brushing and toothpaste occurs following the } \\
\text { fluoride recommendation. The provider asks questions on frequency and methods about } \\
\text { the child's oral hygiene habits. } \\
\text { Another QAE arrangement occurs with age-appropriate tooth brushing instructions. } \\
\text { "...by brushing, you're doing two things, one you're keeping his teeth clean, and you're } \\
\text { also getting him used to having him in your mouth so teeth brushing becomes second } \\
\text { nature." After this thorough conversation about oral health, the provider performs a } \\
\text { screening and explains the application of fluoride varnish. He/she mentions that the } \\
\text { practice's goal is to examine the child's teeth each time he is here and "If we notice that } \\
\text { he has a problem with his teeth at a young age, we'll send him to a dentist." } \\
\text { The provider discusses the child's latest developments again as well as screen-time and } \\
\text { car seat use. The appointment concludes with a discussion of vaccinations. }\end{array}$ & $\begin{array}{l}\text { QAE } \\
\text { Simple language }\end{array}$ \\
\hline
\end{tabular}




\begin{tabular}{|c|c|c|c|}
\hline ID 8 & & $\begin{array}{l}\text { The provider addresses the child directly right away during this interaction. The (male) } \\
\text { child is presumably } 3 \text { years old because the provider says, "I can't believe that you're } 3 \\
\text { already!" They discuss vaccinations the child is due for and the provider asks how the } \\
\text { child is doing and what he is eating. There is a discussion about solid diet, but none of it } \\
\text { relates to oral health. The provider utilizes questioning when talking about liquid diet. } \\
\text { He/she determines that the child drinks water "with a little flavor in it". They talk about } \\
\text { brushing, toothpaste and fluoride use. The provider gives advice and presents } 2-3 \\
\text { concepts at one time when talking about oral hygiene habits. The caregiver is assertive } \\
\text { and reports that the child was "having dental problems last year". } \\
\text { The provider asks what types of problems they had and confirms that the caregiver has } \\
\text { established a dental home for the child. He/she provides advice concerning liquid diet } \\
\text { and begins a physical exam about halfway through the appointment. The provider tells } \\
\text { the caregiver "I can see where he's had some build up on here" when he/she looks in the } \\
\text { child's mouth. He/she tells them about the fluoride varnish and gives instructions for } \\
\text { eating and drinking afterwards. The patient is inquisitive about the fluoride treatment and } \\
\text { the provider answers his/her questions. } \\
\text { As the provider continues examining the child, he/she gives advice about vaccinations } \\
\text { and asks if the caregiver has any further questions. The caregiver asks about a skin } \\
\text { condition and the provider gives advice on products. The provider exits the appointment } \\
\text { by affirming that they do not need to see the child for a year until his next well-child visit } \\
\text { and tells them to "keep up the good work." }\end{array}$ & \begin{tabular}{|l|} 
QA \\
Inquisitive/assertive \\
caregiver \\
2-3 concepts at a time
\end{tabular} \\
\hline ID 12 & Sick & $\begin{array}{l}\text { The provider immediately thanks the caregiver for participating in the study. He/she } \\
\text { addresses the (male) child patient directly, asking how he is feeling. The caregiver } \\
\text { answers, listing a number of symptoms. The child is very upset and crying. The provider } \\
\text { does a physical exam with the child in the caregiver's lap. The exam includes an oral } \\
\text { screening. The provider explains the illness, diagnosis, and treatment. He/she uses } \\
\text { questioning and advice discussing oral hygiene habits next, but lacks explanation. The } \\
\text { provider does use simple language and only presents 2-3 concepts at a time when } \\
\text { providing advice about toothrushing and toothpaste use as well as liquid diet. The } \\
\text { provider explains the treatment for the child's illness once more before exiting the } \\
\text { appointment. }\end{array}$ & $\begin{array}{l}\text { QA } \\
\text { Simple language } \\
\text { Presents 2-3 concepts } \\
\text { at a time }\end{array}$ \\
\hline
\end{tabular}




\begin{tabular}{|c|c|c|c|}
\hline ID 14 & Sick & $\begin{array}{l}\text { The provider enters the appointment and promptly begins questioning the caregiver } \\
\text { about the (female) child's symptoms. He/she also addresses the child directly, asking her } \\
\text { how she is feeling. The provider begins an exam by first looking in the child's mouth. } \\
\text { He/she makes a diagnosis and recommends treatment. } \\
\text { The children switch places and another (male) child is assessed. The provider does a } \\
\text { physical exam on this sick child and discusses treatment. He/she does an oral screening } \\
\text { "Stick your tongue out. Come over here and l'll look at your teeth. "Ahh" Mommy's doing } \\
\text { a good job, they look great" and gives some feedback. The provider and caregiver } \\
\text { continue conversing about the child's illness and treatment until the last part of the } \\
\text { appointment when the provider inserts oral health information. He/she uses simple } \\
\text { language while providing advice and explanations concerning liquid diet, homecare } \\
\text { habits and topical fluoride varnish. The provider does not utilize any questioning but } \\
\text { presents } 2-3 \text { concepts at a time while making oral hygiene recommendations. The oral } \\
\text { health interaction is brief, but the provider touches on the important topics. The } \\
\text { interaction concludes with confirmation of treatment for the children's illnesses. }\end{array}$ & $\begin{array}{l}\text { AE } \\
\text { Presents } 2-3 \text { concepts } \\
\text { at a time }\end{array}$ \\
\hline
\end{tabular}




\section{REFERENCES}

1. Pahel BT. Referrals for dental care in a medical office-based preventive dental program. Diss. The University of North Carolina at Chapel Hill, 2008: 259 pages

2. Pahel BT, Rozier RG, Stearns SC, Quinonez RB. Effectiveness of preventive dental treatments by physicians for young medicaid enrollees. Pediatrics. 2011; 127(3):e682-9.

3. Peirce KM, Rozier RG, Vann WF Jr. Accuracy of pediatric primary care providers' screening and referral for early childhood caries. Pediatrics. 2002; 109; e82

4. Cleland J, de la Croix A, Cotton P, Coull S, Skelton J. Student-patient communication during physical examination. Clin Teach. 2013;10(2):84-7.

5. Opel DJ, Robinson JD, Heritage J, Korfiatis C, Taylor JA, Mangione-Smith R. Characterizing providers' immunization communication practices during health supervision visits with vaccine-hesitant parents: A pilot study. Vaccine. 2012;30(7):1269-75.

6. Laidsaar-Powell RC, Butow PN, Bu S, et al. Physician-patient-companion communication and decision-making: A systematic review of triadic medical consultations. Patient Educ Couns. 2013; 91(1):3-13.

7. Slade GD, Rozier RG, Zeldin LP, Margolis PA. Training pediatric health care providers in prevention of dental decay: Results from a randomized controlled trial. BMC Health Serv Res 2007;7:176-86.

8. American Academy of Pediatrics. Section on Oral Health: Bright Futures. Available at: https://brightfutures.aap.org/Pages/default.aspx; Accessed October 2013.

9. Kranz AM, Pahel BT, Rozier RG. Oral literacy demand of preventive dental visits in a pediatric medical office: A pilot study. Pediatr Dent. 2013; 35(2):E68-74.

10. Beil H, Rozier RG, JS Preisser, Stearns S, Lee JY. Effect of Early Preventive Dental Visits on Subsequent Dental Treatment and Expenditures. Med Care. 2012; 50(9): 749-56.

11. Gibbs, G. (2014). Using software in qualitative analysis. In U. Flick (Ed.), The SAGE handbook of qualitative data analysis. (pp. 277-295). London: SAGE Publications Ltd. 
12. Peräkylä, Anssi, and Johanna Ruusuvuori. Analyzing Talk and Text. 2011. Pp. 529-43 in the Sage Handbook of Qualitative Research. Sage.

13. Sandelowski, M. Sample size in qualitative research. Research in Nursing \& Health,1995. 18, pp. 179-83.

14. Guest, Greg, Arwen Bunce, Laura Johnson. "How Many Interviews Are Enough? An Experiment with Data Saturation and Variability." Field Methods 18:59-82.

15. Rozier RG, Stearns SC, Pahel BT, Quinonez RB, Park J. How North Carolina program boosted preventive oral health services for low-income children. Health Aff 2010; 29:2278-85.

16. Nelson JM, Vos MB, Walsh SM, O'Brien LA, Welsh JA. Weight managementrelated assessment and counseling by primary care providers in an area of high childhood obesity prevalence: current practices and areas of opportunity. Child Obes. April 2015; 11(2)194-201.

17. Quinonez RB, Kranz AM, Lewis CW, Barone L, Boulter S, O'Connor KG, Keels MA. Oral health opinions and practices of pediatricians: updated results from a natural survey. Acad Ped 2014; 14(6):616-23.

18. Lewis CW, Grossman DC, Domoto PK, Deyo RA. The role of pediatrician in the oral health of children. A national survey. Pediatrics. 2000; 106:E84.

19. Rozier RG, Horowitz AM, Podschun G. Dentist-patient communication techniques used in the United States. The results of a national survey. J Am Dent Assoc 2011; 142(5): 518-30.

20. Horowitz AM, Canto MT, Child WL. Maryland adults' perspectives on oral cancer prevention and early detection. J Am Dent Assoc 2002; 133:

21. Tongue JR, Epps HR, Forese LL. Communication skills for patient-centered care: research-based, easily learned techniques for medical interviews that benefit orthopedic surgeons and their patients. J Bone Joint Surg Am. 2005; 87(3):65258.

22. Isong IA, Luff D, Perrin JM, Winickoff JP, Ng MW. Parental perspectives of early childhood caries. Clin Pediatr. 2012; 51(1): 77-85.

23. Fidyk L, Ventura K, Green K. Teaching nurses how to teach. $J$ Nurses Prof $D$. $2014 ; 30(5): 248-53$.

24. Peter D, Robinson P, Jordan M, Lawrence S, Casey K, Salas-Lopez D. Reducing readmissions using teach-back: enhancing patient and family education. $J$ Nurs Adm. 2015; 45(1):35-42. 
25. Bredart A, Bouleuc C, Dolbeault S. Doctor-patient communication and satisfaction with care in oncology. Curr Opin Oncol. 2005; 17(14):351-54.

26. Arora N. Interacting with cancer patients: the significance of physicians' communication behavior. Soc Sci Med. 2003; 57(5):791-806.

27. Platt FW, Keating KN. Differences in physician and patient perceptions of uncomplicated UTI symptom severity: understanding the communication gap. Int J Clin Prac. 2007;61(2):303-308.

28. Ha FJ, Anat DS, Longnecker N. Doctor-patient communication: a review. Ochcner J. 2010;10:38-43.

29. Harms C, Young JR, Amsler F, Zettler C, Scheidegger D, Kindler CH. Improving anaesthetists' communication skills. Anaesthesia. 2004; 59(2):166-172. 